the solar corona and the zodiacal light. In a series of well-planned, adventurous and successful expeditions, in the Sudan for the 1952 eclipse, in an open aircraft at $30,000 \mathrm{ft}$. for the 1954 eclipse, over the Pacific in another aircraft in 1955, in the high Andes in 1958, he has extended optical measures until we now have reliable curves of brightness and polarization from the inner corona to the zodiacal light region $70^{\circ}$ away. With M. F. Ingham he has photographed the zodiacal light spectrum with higher resolution than hitherto attained; their results have considerably altered our views on electron densities in interplanetary space and on the light scattered by interplanetary dust. They have also shown beyond doubt that the zodiacal light is sometimes variable. In 1956, and again in 1957, Blackwell and A. Dollfus made pioneer photographs of solar granulation from a balloon at 15,000-20,000 ft., using an 11-in. telescope, and demonstrated that most of the loss of telescope definition from bad day-time seeing can be avoided in this way. Dr. Blackwell is one who believes that observational astronomers must at all times seize upon any new techniques which promise significant advantage over older methods, and has acted on this belief with notable success.

Biology at Melbourne (Monash): Prof. A. J. Marshall

Dr. A. J. Marsha.li, reader in zoology and comparative anatomy in the University of London at St. Bartholomew's Hospital Medical College, where he is head of the Department, has been appointed to the chair of biology in the new Monash University in Melbourne, Australia. Dr. Marshall is an Australian by birth and upbringing; soon after entering the University of Sydney he joined the Oxford University Expedition to the New Hebrides, and then went to Oxford to help work out the results before returning to Sydney to finish his course and to graduate. During 1941-45 he was engaged in military service in northern Australia and New Guinea, and commanded the independent infantry "Jockforce" in the Wewak Campaign. In 1946 he returned to Oxford, where he obtained his D.Phil. and, later, D.Sc. degrees. In 1949 he resigned his Beit Memorial Research Fellowship to accept his appointment at St. Bartholomew's.

Dr. Marshall has always been a naturalist, and in his early years published a number of papers on natural history subjects in Australian journals. Under academic influence, and the guidance of Dr. John R. Baker and the late Dr. F. H. A. Marshall, his research interests concentrated on the physiology of reproduction in vertebrates, especially in its relation to behaviour, migration, and the ecology of breeding seasons. He has been strikingly successful in combining field and laboratory work by using the changing environment as a kind of natural laboratory. Key localities and situations, such as deserts, the aretic, early springs, and unusually severe winters, have been selected, and free-living birds, fishes, reptiles and mammals have been collected at periods, often in successive years, that were expected to yield the most valuable results upon subsequent histological investigation of their sexual cycles. He has always kept one foot in the field while the other was in the laboratory. One of his most important discoveries is the post-breeding metamorphosis of the seminiferous tubules in non-mammalian vertebrates into a mass of cholesterol-positive lipoid material which contains progesterone, and the somatic and psychological effects of the action of this hitherto undescribed endocrine gland. A very long series of papers by Marshall and his colleagues record these and cognate researches, crowned by his penetrating study of reproductive physiology and behaviour of the bower birds published by the Clarendon Press in 1954. Prof. Marshall will not only build up a first.rate teaching department at Monash, but will also undoubtedly establish a school of research in fieldendocrinology, for which Australia offers unbounded opportunities, that will redound both to his own credit and that of his colleagues in the Old Country who first guided his steps towards this rewarding subject of research.

\section{Cyto-Genetics at the Royal Botanic Gardens, Kew :}

Dr. Keith Jones

Dr. KeIth Jones, a graduate of the University College of Wales, Aberystwyth, has been appointed a principal scientific officer at the Royal Botanic Gardens, Kew, to undertake research in cyto-geneties. Since 1948 he has been in charge of the Department of Cytology at the Welsh Plant Breeding Station, Plas Gogerddan, Aberystwyth, where his investiga. tions have been connected mainly with European species of the Gramineae, in particular those of the genera Agrostis, Anthoxanthum, Dactylis and Holcus. $\mathrm{He}$ was awarded a doctorate by his University in 1957 for his thesis on "Species Differentiation in Agrostis", and recently spent a year studying at the Plant Research Institute, Ottawa, as a postgraduate fellow of the National Research Council of Canada.

Although Kew is internationally renowned for the beauty of its Gardens, it is primarily a research establishment concerned with the classification, determ. ination and description of plants. For more than a hundred years its vast collections of herbarium specimens supplemented by living plants have been the subject of intensive morphological and anatomical studies. On the other hand, these unrivalled living collections, estimated to include some 45,000 species and varieties, have received comparatively little attention from the cyto-geneticists, and probably half of them have never been examined cytologically. Here, with such a wealth of desirable material, constantly being enriched by new discoveries, and representative of all groups of vascular plants and of very diverse phytogeographical regions, there is a unique opportunity for extensive cytological and genetical investigations. While the urgent need at present is for karyological studies, especially the determination of numbers and forms of chromosome sets, other lines of research, such as the genetical study of species and putative hybrids impossible of satisfactory classification by ordinary taxonomic methods, are also very necessary. It is hoped that this closer association of systematic botany, cytology and geneties at Kow will lead to the resolving of many difficult taxonomic problems and ultimately to a much improved and more natural system for the flowering plants.

\section{Royal Society of Edinburgh : New Fellows}

AT a meeting of the Royal Society of Edinburgh, held on March 7, the following were elected Fellows of the Society: Dr. I. R. C. Batchelor, physician superintendent, Dundee Royal Mental Hospital, and head of the Department of Psychiatry, University of St. Andrews; Dr. D. Bijl, lecturer in natural philosophy, University of St. Andrews ; Prof. T. L. Cottrell, Department of Chemistry, University of 